\title{
Local Residential Sorting and Public Goods Provision: A Classroom Demonstration
}

\author{
Keith Brouhle, Jay Corrigan, Rachel Croson, Martin Farnham, Selhan Garip, \\ Luba Habodaszova, Laurie Tipton Johnson, Martin Johnson, and David Reiley
}

\author{
April 2004
}

\begin{abstract}
This classroom exercise illustrates the Tiebout (1956) hypothesis that residential sorting across multiple jurisdictions leads to a more efficient allocation of local public goods. The exercise places students with heterogeneous preferences over a public good into a single classroom community. A simple voting mechanism determines the level of public good provision in the community. Next the classroom is divided in two, and students may choose to move between the two smaller communities, sorting themselves according to their preferences for public goods. The exercise places a cost on movement at first, then allows for costless sorting. Students have the opportunity to observe how social welfare rises through successive rounds of the exercise, as sorting becomes more complete. One may also observe how immobile individuals can become worse off because of incomplete sorting when the Tiebout assumptions do not hold perfectly.
\end{abstract}

Key words: classroom experiments, public goods, residential sorting, Tiebout hypothesis.

JEL codes: A22, H42, H73

The authors are graduate research assistant at the University of Illinois at Urbana-Champaign, assistant professor at Kenyon College, associate professor at the University of Pennsylvania, graduate student at the University of Michigan, graduate research assistant at Virginia Tech, assistant professor at Indiana University Kokomo, assistant professor at Denver University, assistant professor at the University of California at Riverside, and associate professor at the University of Arizona, respectively. We appreciate comments from participants at the Southern Economic Association conference in New Orleans, from Lucie Schmidt at Williams College, and from three anonymous reviewers. The authors were participants in the 2002 NSF Workshop on Classroom Experiments in Economics, and gratefully acknowledge the support of NSF grant GA10210.

Correspondence: Jay Corrigan, Department of Economics, Kenyon College, Gambier, OH 43022. E-mail: corriganj@kenyon.edu. Tel: 740-427-5281. Fax: 740-427-5276. 


\section{Local Residential Sorting and Public Goods Provision: A Classroom Demonstration}

Students in undergraduate public finance courses learn that market provision of public goods is generally inefficient because of the nonexcludable and nonrival characteristics of such goods. Centralized government provision of locally consumed public goods may also prove inefficient because of heterogeneous preferences or heterogeneous opportunity costs. Accordingly, neither centralized nor market institutions are likely to efficiently provide local public goods.'

In a seminal paper, Tiebout (1956) suggested that the problem of efficient local public goods provision can be solved through political institutions whose outcomes resemble those of competitive markets..$^{2}$ Tiebout argued that if a sufficient number of communities existed to accommodate the different types of preferences, individuals could sort themselves into communities that provide their most desired (feasible) bundle of public goods and taxes. Competition between communities ensures that local public goods are provided at the lowest cost. Tiebout assumed that each community imposed a head tax equal to the cost of provision divided by the population of the community. He further assumed: a large number of communities exist to choose from; an optimal community size for each pattern of tastes; no externalities or economies of scale; residents have full information about available options; and sorting is costless. ${ }^{3}$ The resulting equilibrium allocation will maximize social welfare.

The following classroom demonstration is designed to illustrate the efficiency gains that can arise from decentralization and local sorting, as well as problems that arise when certain assumptions of the Tiebout model are not met. The classroom at first 
comprises a single community of students with heterogeneous preferences for a public good (dorm parties); the students determine the level of taxation to be used for public good provision via a simple voting mechanism. Next, the classroom divides into two communities, each of which determines its own level of public good provision. Then the students have the opportunity to relocate to the community where the bundle of public goods and taxes better suits their tastes. At first some students must stay in their original location, but in the final treatment all students become mobile. After each round of sorting, each community determines a new level of public good provision. Students see how welfare rises as sorting becomes more complete. This game illustrates the Tiebout sorting equilibrium and the possibility of efficient provision of local public goods. It also highlights the usefulness of markets in general and the assumptions necessary for a wellfunctioning market to reach an efficient outcome. The third round of the exercise may foster classroom discussion about white flight from inner-city school districts, as it shows how some immobile individuals become worse off when mobile individuals move.

\section{PROCEDURES}

The classroom demonstration takes about 30 minutes, which leaves time for class discussion afterward. The demonstration will work in classes with as few as six students or as many as 100 students, but the ideal class size is probably between 20 and 40 . For large classes, teaching assistants will be required to aid in the counting of votes. The exercise, while designed primarily for an undergraduate public-finance course, can be employed in any political science, public policy, sociology, or economics course that covers government provision of public goods or services. 
Each student receives a packet that includes: (1) a colored set of instructions with record sheet (e.g., half the students receive red and half yellow), (2) a different colored ribbon or index card (e.g., half the students receive white and half blue), and optionally (3) four ballots on which to write votes. The color of the instructions denotes each student's value for the public good, and the color of the ribbon or index card denotes each student's mobility (whether one may change communities). It works well to put all the materials for each student into large envelopes in advance of the class.

The overall distribution of packets in the class should be approximately half red and half yellow, but the red and yellow packets should not be evenly distributed between the two sides of the classroom. For reasons that will become apparent, we recommend that packets be unevenly distributed across the classroom after the students are seated. For example, two-thirds of the packets on the right side of the classroom should be red, while two-thirds of the packets on the left side of the classroom should be yellow. Students are asked to open their packets and follow along as the instructions are read aloud. The instructions include examples of how students calculate their individual welfare at the end of each of four academic years. The only difference between the red instructions and the yellow instructions is the assigned formula for valuation of the public good, defined as dormitory parties and other social events.

The students are informed that for Year 1, they are residents in a single dorm comprised of all students in the classroom. In order to calculate after-tax welfare (explained further below), each student is endowed with a spending allowance of $\$ 1000$ per academic year. The dorm must collectively choose a level of entertainment and associated per capita taxation between $\$ 0$ and $\$ 100$. Let $E$ be the level of dorm parties 
and entertainment. ${ }^{4}$ The per capita cost of a given level of entertainment is $E$ itself, indicating that the unit cost per capita is $\$ 1$. Taxes, $T$, are levied to cover the cost of entertainment, so that $T=E$. Benefits derived from dorm parties are $2 \times E$ for students with red instructions (high valuers) and $0 \times E$ for students with yellow instructions (low valuers) (i.e., low-valuation students derive no benefit from dorm parties). Net benefits as a function of taxes can then be written as $2 T-T$ for high-valuation students and $-T$ for low valuation students. The value multiplied with the level of entertainment is referred to as "personal value multiplier" on the instruction sheet. The instructor should stress to the students that they have been assigned their personal value multiplier, because some students may feel that because the value is "personal," they should be able to select their own.

All students receive instructions revealing the gross benefit they receive from parties and social events. By assumption, a unit of "social events" costs \$1. Hence, the marginal benefit of contributing always exceeds the marginal cost to the high-valuation students, whereas the marginal cost always exceeds the marginal benefit to the lowvaluation students. In order to better motivate students to participate in this demonstration, instructors may wish to announce in advance that at the end of the experiment one student will be selected randomly to receive some fraction of his or her payoff in cash (e.g., 1/1000th).

In each year of the game, the entire class votes for a level of social event taxation.s The simple public choice mechanism, which is repeated in each year, works as follows: The instructor announces three possible choices of $T$ on the ballot $-\$ 0, \$ 50$, or $\$ 100$. 
Residents are polled on their preferred level. Low-valuation residents should prefer $T=$ $\$ 0$ and high-valuation residents should prefer $T=\$ 100$. The $T=\$ 50$ option allows a choice for students who are either confused or altruistic and makes students less suspicious that the deck is stacked in favor of a certain outcome. After tallying the votes, the instructor sets the level of $T$ at the weighted average of the three options: $T^{*}=p_{0}(\$ 0)+p_{50}(\$ 50)+p_{100}(\$ 100)$, where $p_{i}$ is the fraction of votes in favor of choice $i$. Calculating the outcome of this vote is the most time consuming part of the exercise. In a class of 30-40 students, a simple hand count might be utilized, but in larger classes paper ballots may help to facilitate the process.

The instructor enters the votes each option receives into a spreadsheet, which calculates the voted-upon tax level, $T^{*}{ }^{*}$ Students calculate their after-tax welfare after each vote according to the $T^{*}$ that has been chosen and announced. For high-valuation students the calculation is $\$ 1000+\left(2 T^{*}\right)-T^{*}$, for low valuation students the calculation is $\$ 1000+\left(0 T^{*}\right)-T^{*}$ ? After students have an opportunity to compute their after-tax welfare, the instructor should ask for a show of hands on the questions: "How many of you are receiving after-tax welfare greater than your initial spending allowance of $\$ 1000$ ?" and "How many have less than your initial spending allowance of $\$ 1000$ ?" Individuals who raise their hand to the first question are high-valuation types, assuming the students have computed their individual welfare correctly. The balance of the class is made up of low-valuation types. The instructor will then enter the number of each type into the spreadsheet to calculate the social welfare $\left(W_{s}\right)$ for the class; e.g., $W_{s}=\left(N_{H}\right)(1000$ $\left.+2 T^{*}-T^{*}\right)+\left(N_{\iota}\right)\left(1000-0 T^{*}-T^{*}\right)=\left(N_{H}\right)\left(1000+T^{*}\right)+\left(N_{\iota}\right)\left(1000-T^{*}\right)$, where $N_{H}$ 
equals the number of high-valuation students and $N_{L}$ the number of low-valuation students.

In Year 2, the classroom is divided into two separate dorms (e.g., "Left" and "Right"). This can be done by means of a volunteer or teaching assistant in the back of the classroom, and a roll of string or toilet paper. The roll is tossed to the volunteer and allowed to unroll in the air, neatly dividing the class roughly in half, into "left" and "right" dormitories. Each half of the class now votes on a separate level of taxation, $T$, and hence public good provision, $E$. Again, students calculate their after-tax welfare and the instructor enters $T_{\llcorner}^{*}$ for left and $T_{R}^{*}$ for right into the spreadsheet. In each community, the instructor now asks: "How many of you have improved your after-tax welfare from the previous year's after-tax welfare?" and "How many of you now have a lower after-tax welfare than you did in the previous year?" In contrast to Year 1, this and all subsequent years frame the question in terms of after-tax welfare relative to the previous year. This is done to illustrate that most people become better off as communities separate into different types, even low types who are receiving a net loss from taxation.

If packets were initially distributed in an uneven fashion (such as the recommended split of two-thirds red in one half of the class and two-thirds yellow in the other half of the class), then social welfare will rise in Year 2. This occurs because the level of $T$ chosen in the two communities will reflect the differences in preferences for the public good. Different levels of the local public good will provide a clear signal to residents about the community they will want to choose in Year 3 when mobility is allowed. ${ }^{8}$ In the authors' experience, simply allowing students to observe the different 
tax levels imposed by the two dorms has provided a sufficient signal to prompt students to sort themselves according to their preferences. An alternative would be to allow students to send explicit signals. For example, at this point in the demonstration students in the right dorm might announce "If you like parties, this is the dorm for you!" Likewise, students assigned to the left dorm might announce "If you want lower taxes, move Left."

In Year 3, certain individuals are permitted to switch communities to take advantage of a more appealing package of a public good and related tax. Students who change communities should physically change their location in the classroom. Those who have received a blue ribbon or index card are entitled to move freely. They can be thought of as having sufficient additional income to afford some fixed cost of moving, or as having no other nonfinancial constraints on moving. A toll bridge between the communities may be set up, in which the instructor collects a toll in the form of the blue card or ribbon from anyone who wishes to pass. Those without a blue pass must remain in their original community. After sorting, voting for tax rates takes place again in both communities and $T^{*}$ for each community is calculated. Students again calculate their after-tax welfare, and the instructor again surveys the class and calculates social welfare. The instructor should repeat the questions: "How many of you have improved your aftertax welfare from the previous year's after-tax welfare?" and "How many of you now have a lower after-tax welfare than you did in the previous year?"

It is worth noting that while social welfare will have risen in Years 2 and 3, the welfare of some individuals may have fallen. These will be either low types whose taxes have increased over the previous round, or high types whose taxes have decreased. In the 
classroom discussion at the end, especially with regards to costly mobility, it is worth noting why the welfare of some individuals fell in Years 2 and 3.

In Year 4, individuals are now told that mobility is costless. Everyone is allowed to freely choose the community that best suits them. Once again, some students will migrate across the classroom from one community into another. When students have settled into their chosen communities, $T_{t}^{*}$ and $T_{*}^{*}$ are determined, individual and social welfare are calculated, and results are posted.

As a final gesture, all students are asked at this point to hold up their colored record sheet. The students should observe that most, if not all, residents of each community now have the same colored instruction sheet, and hence the same valuation of the local public good. As the Tiebout hypothesis predicts, individuals sort themselves into communities made up of others with similar preferences for public goods, in this case by the red and yellow record sheets.' They should also note that everyone's welfare rose in Year 4, and social welfare moved to the highest level in the demonstration.

\section{DISCUSSION}

This exercise can generate a rich class discussion. To begin, the instructor may use the exercise to highlight the predictions and assumptions of the model.

Assuming the packets were distributed in an uneven fashion (as suggested), the two communities (dorms) in Year 2 should choose different levels of taxation depending upon their dominant preference type. The dorm with more high types should vote for higher taxes; the other dorm, with more low types, should vote for lower taxes. On average, more of each type had their preference more closely satisfied in Year 2 versus 
Year 1, increasing total social welfare. This is not to say, though, that everyone's individual welfare improved. Low types are forced to spend some of their allowance on dorm social events (more so in one dorm than the other).

When partial mobility was allowed in Year 3 (only the people with blue cards or ribbons could switch dorms), the equilibrium level of the local public good in the two communities should further diverge. In each dorm, some individuals in the minority were able to move to the other community. Social welfare further improved.

Once mobility was completely free, the Tiebout predictions should be realized: as everyone should move to the dorm of their choice. Those with preferences for spending their money on dorm parties and social events live in a dorm with a high social-event tax, whereas the other students end up keeping their entire spending allowance and live in a dorm with no community-provided social events.

In the process of a classroom discussion, certain conclusions should be emphasized. First, both types of individuals experience welfare gains by the end of the game. Low-valuation students start with a negative net benefit and end with a net benefit of zero..$^{10}$ High-valuation students will also improve their welfare compared to the initial welfare prior to an increase in a number of communities and free mobility. When students are not allowed to move, (i.e., in Year 2 or without a blue ribbon or card in Year 3), some may experience a drop in their welfare compared to Year 1. Class discussion questions may include the following: What changes result in increases in individual welfare over time? Does welfare only go up for an individual when the individual moves? What about individuals who never move? Does their welfare change as a result of other people moving? When does the migration of other people raise an individual's 
welfare, and when does it lower it? Does the situation improve in aggregate? What about for each individual?

The classroom discussion should focus on how individual and total welfare change over the successive years of the demonstration, and emphasize changes in social welfare. It is worth showing the social welfare calculation from the spreadsheet for each year, so students can observe the progression. By the end of Year 4, most students realize that when similar individuals perfectly sort themselves into communities according to their taste for a public good, social welfare is maximized.

The game and the above discussion of it should vividly illustrate the concepts of the Tiebout model for the students. With that accomplished, a broader discussion can begin regarding the complexities of public goods and the importance of the assumptions of the model. A good place to start might be having students discuss their own experience with residential choice and the communities in which they have lived. How did their family decide where to locate? Did the quality of the schools or other local public goods like overall safety (police, fire protection) or amenities (parks, libraries) matter to their decision? Do they believe everyone in their community wants exactly the same thing from the local government? In other words, just how complete is the residential sorting they observe in the real world? The instructor may list the different residential selection factors on the board and then ask whether the assumptions are likely to hold in the real world.

In general, it is important to emphasize the implications of relaxing the model's assumptions. There are many questions the instructor could pose. What happens if we have more than two types of residents, but only two communities? Can welfare be 
perfectly maximized by costless sorting? Or, what if there are differences in the efficient size of the community for the provision of different local public goods? In this case, a single household would belong to multiple local-public-good communities (for example, the city provides police protection, a district provides schools, and a county provides parks). Will efficient levels be reached?

Apart from Tiebout's assumptions, in this experiment we assumed that all students have the same level of income. How could the sorting outcome differ in the case of heterogeneous income levels and homogenous preferences? What about with both heterogeneous income and heterogeneous preferences?

Perhaps most interesting is a discussion of the costless mobility assumption. Students should be able to come up with several reasons why moving might be costly. For example, some residents may need to locate near places of employment, which is a function of individuals' labor mobility. In addition, there are fixed costs of moving, such as fees involved in buying and selling a house or renting an apartment. Other individuals may find that nonpecuniary costs are equally important. For instance, many people value living near their relatives and friends, or simply dislike moving and adjusting to a new environment. In this case, the sorting is incomplete and the equilibrium outcome is inefficient.

The implications of imperfect sorting are wide ranging. For example, heterogeneous income levels and resulting differences in mobility may result in inferior public education opportunities for some families that place high valuation on quality education. A class discussion of state and federal grants and subsidies to local education can follow from this, as well as debate over school voucher programs. In addition, other 
barriers to mobility such as housing discrimination might prevent optimal sorting outcomes.

The basic framework of this demonstration is flexible enough to allow for numerous extensions emphasizing different aspects of local public good provision. For example, instructors in advanced courses may want to introduce multiple public goods, then allow students to coordinate to form an endogenously determined number of distinct communities. Instructors can also experiment with different voting mechanisms, for example replacing the weighted-average mechanism with a simple plurality rule. This is a fairly straightforward alternative to the mechanism described above, and in the authors' experience it leads to the same sorting outcome. Yet another alternative would be for instructors to allow for a median-voter setup where mayoral candidates commit to a level of $T$. Endogenizing candidates' platform choice in this way would add time and complication to the demonstration, but this may be warranted for advanced classes in political economy.

\section{FURTHER READING}

We briefly surveyed the classic papers from the public good provision and local residential sorting literatures. This discussion is meant primarily as a quick reference for instructors, and as a guide for students interested in further studying this area of economic thought.

The starting point of the literature on the provision of public goods was Samuelson's seminal piece "The Pure Theory of Public Expenditure” (1954), which showed that the private production of public goods is inefficient. Because markets are 
unable to provide public goods, attention focused on the possibility of government provision of these goods. However, without market prices as signals, the fundamental problem is to ascertain the individual's valuation of a public good. Clarke (1971), Groves (1973), and Groves and Ledyard (1977) made important contributions to this literature by designing preference revelation mechanisms. Tiebout (1956), on the other hand, argued that we could return to the principles of the market to uncover consumer's valuation for some types of public goods. For local public goods at least, competition among local jurisdictions can lead to an efficient provision. Consumers, facing a number of communities with different levels of taxes and local public goods, reveal their true valuation of the local public good by moving to the community that most closely mirrors their preferences. This approachable article demonstrates to undergraduates that important innovations in economic theory can be conceived and expressed in a nontechnical way. For a good general discussion of the Tiebout model in the context of fiscal federalism and an undergraduate public-finance class, see Hyman (1993) or Stiglitz (2000).

The conceptual ideas Tiebout presented have made a lasting contribution in many different areas of the social sciences. In the field of economics, one can find the Tiebout hypothesis playing an important role in questions of school choice (Rubinfield et al. 1987) and tax capitalization (Bloom et al. 1983; Mieszkowski and Zodrow 1989). In addition, Tiebout's basic idea that communities compete for residents has been borrowed in the literature about firm location and tax competition policy (Brueckner 2000). The idea of sorting in a nonspatial dimension is also important in Buchanan's (1965) work on clubs. 
Tiebout's contribution also extends to other fields. In particular, political scientists have explored whether the Tiebout results apply in different political or voting regimes (Kollman, Miller and Page 1997). The Tiebout model also underlies research on the political implications of devolution, especially the expectation that state governments will "race to the bottom" in their provision of social welfare benefits, competing for productive capital and avoiding redistributive policies (Brace 1993; Peterson 1981; Donahue 1997). Political scientists have also investigated the micro-foundations of the Tiebout model, especially whether individuals are sufficiently informed and mobile to sort themselves (Bickers and Stein 1998; Lowery, Lyons and DeHoog 1995; Peterson and Rom 1989; Schenider, Teske, Mintrom and Best 1993). 


\section{REFERENCES}

Bloom, H. S., H. F. Ladd, and J. Yinger. 1983. Are property taxes capitalized into house values? In Local provision of public services: The Tiebout model after twenty-five years, ed. G. R. Zodrow. New York: Academic Press.

Bickers, K. N., and R. M. Stein. 1998. The microfoundations of the Tiebout model. Urban Affairs Review. 34 (1): 76-93.

Brace, P. 1993. State government and economic performance. Baltimore: Johns Hopkins University Press.

Brueckner, J. K. 2000. A Tiebout/tax-competition model. Journal of Public Economics 77 (2): 285-306.

Buchanan, J. M. 1965. An economic theory of clubs. Economica 33 (February): 1-14.

Clarke, E. H. 1971. Multipart pricing of public goods. Public Choice 11 (Fall): 17-33.

Donahue, J. D. 1997. Tiebout? or not Tiebout? The market metaphor and America's devolution debate. Journal of Economic Perspectives 11 (4): 73-82.

Groves, T. 1973. Incentives in teams. Econometrica 41 (4): 617-631.

Groves, T. and J. Ledyard. 1977. Some limitations of the demand-revealing process. Public Choice 29 (2): 107-124.

Hyman, D. N. 2002. Public finance: A contemporary application of theory to policy. 7th ed. New York: The Dryden Press.

Kollman, K., J. H. Miller, and S. E. Page. 1997. Political institutions and sorting in a Tiebout model. American Economic Review 87 (5): 977-992. 
Lowery, D., W. E. Lyons, and R. Hoogland DeHoog. 1995. The empirical evidence for citizen information and a local market for public goods. American Political Science Review 87 (3): 705-7.

Mieszkowski, P. and G. R. Zodrow. 1989. Taxation and the Tiebout model: the differential effects of head taxes, taxes on land rents, and property taxes. Journal of Economic Literature 27 (3): 1098-1146.

Peterson, P. 1981. City Limits. Chicago: University of Chicago Press.

Peterson, P. and M. Rom. 1989. American federalism, welfare policy, and residential choices. American Political Science Review 83 (3): 711-28.

Rosen, H. S. 2005. Public finance. 7th ed. Boston: McGraw-Hill Irwin.

Rubinfeld, D. L., P. Shapiro, and J. Roberts. 1987. Tiebout bias and the demand for local public schooling. Review of Economics and Statistics 69 (3): 426-437.

Samuelson, P. A. 1954. The pure theory of public expenditure. Review of Economics and Statistics 36 (4): 387-389.

Stiglitz, J.E. 2000. Economics of the public sector. 3rd ed. London: W.W. Norton \& Company .

Teske, P., M. Schneider, M. Mintrom, and S. Best. 1993. Establishing the microfoundations of a macro theory: Information, movers, and the competitive local market for public goods. American Political Science Review 87 (3): 702-13.

Tiebout, C. M. 1956. A pure theory of local expenditures. Journal of Political Economy 64 (5): 416-424. 


\section{Appendix 1. Instructions for Low-Value Residents}

\section{Instructions for the Local Public Good Game}

Suppose you live in a dorm that is deciding how much money to raise for a collective fund that will be spent on parties and social events for your dorm. Your dorm is voting on the amount of money that each resident will equally contribute to the fund for the current school year.

Your room, board, and tuition are already paid for, and you have a spending allowance of $\$ 1000$ at the beginning of each year that you may use freely for entertainment, books, etc.

The dorm will decide on a level of per-capita taxation, $T$, between $\$ 0$ and $\$ 100$, which will be paid out of your $\$ 1000$ spending account. The level of taxation will represent the number of dollars in taxes that you and everyone else in your dorm must each pay. These taxes will be used to sponsor social events in your dorm. Residents of your hypothetical dorm enjoy these social events differently. As a result, you have each been assigned a personal value multiplier. You cannot change the assigned multiplier.

\section{Your personal value multiplier is 0 .}

To calculate the value you derive from your dorm's parties and social events, take your personal value multiplier times $T$. In your case, the value you derive would be $(0 \times T)$. As other people may have different values, we ask that you keep your value private.

In addition to these instructions, you have received a record sheet. You will be using this sheet to record the level of taxes, $T$, imposed by the dorm, as well as the value that you receive from the parties that are funded by these taxes. You will also calculate your after-tax welfare: that is, the value of your spending account $(\$ 1000)$, minus the taxes you pay, plus your own personal value of the social events. Here's the way your record sheet will look:

Level of taxation chosen $(T)$ :

Your spending account

$\$ 1,000$ PLUS

Your value of the social events $(=0 \times T)$ MINUS

Your tax payment for the social events $(=T)$ EQUALS

Your after-tax welfare

To determine the taxation level, the dorm's governing committee will survey its residents. They will ask which of three possible taxation levels you prefer: $\$ 0, \$ 50$, or $\$ 100$. They will then calculate the average of your choices and impose that average as the taxation level. 
Are there any questions so far?

Let's work through an example.

Imagine that there are 10 residents in your dorm, and that 2 of them vote for a level of $\$ 0$ taxes, none vote for $\$ 50$, and 8 vote for $\$ 100$. The average choice is then

$$
\frac{(2 \times \$ 0)+(0 \times \$ 50)+(8 \times \$ 100)}{10}=\$ 80,
$$

so the taxation level will be $\$ 80$ for everyone in the dorm. We have used this information to calculate your after-tax welfare on the following practice worksheet:

Level of taxation chosen $(T): \$ 80$

Your spending account $\quad \$ 1,000$ PLUS

Your value of the social events $(=0 \times T) \quad \$ 0$ MINUS

Your tax payment for the social events $(=T) \quad \$ 80$ EQUALS

Your after-tax welfare $\$ 920$

Are there any final questions before we begin?

Your local government will now conduct its first survey. Take a moment to think about which of the following three options you prefer:

- Taxation of $\$ 0$

- Taxation of $\$ 50$

- Taxation of $\$ 100$

After the vote is taken, we will announce the results and will then proceed to the next year.

At the beginning of each year, you will be given verbal instructions related to that particular year. Please listen carefully and do not hesitate to ask questions if you have them. 


\section{Appendix 2. Instructions for High-Value Residents}

\section{Instructions for the Local Public Good Game}

Suppose you live in a dorm that is deciding how much money to raise for a collective fund that will be spent on parties and social events for your dorm. Your dorm is voting on the amount of money that each resident will equally contribute to the fund for the current school year.

Your room, board, and tuition are already paid for, and you have a spending allowance of $\$ 1000$ at the beginning of each year that you may use freely for entertainment, books, etc.

The dorm will decide on a level of per-capita taxation, $T$, between $\$ 0$ and $\$ 100$, which will be paid out of your $\$ 1000$ spending account. The level of taxation will represent the number of dollars in taxes that you and everyone else in your dorm must each pay. These taxes will be used to sponsor social events in your dorm. Residents of your hypothetical dorm enjoy these social events differently. As a result, you have each been assigned a personal value multiplier. You cannot change the assigned multiplier.

\section{Your personal value multiplier is 2.}

To calculate the value you derive from your dorm's parties and social events, take your personal value multiplier times $T$. In your case, the value you derive would be $(2 \times T)$. As other people may have different values, we ask that you keep your value private.

In addition to these instructions, you have received a record sheet. You will be using this sheet to record the level of taxes, $T$, imposed by the dorm, as well as the value that you receive from the parties that are funded by these taxes. You will also calculate your after-tax welfare: that is, the value of your spending account (\$1000), minus the taxes you pay, plus your own personal value of the social events. Here's the way your record sheet will look:

Level of taxation chosen $(T)$ :

Your spending account

$\underline{\$ 1,000}$ PLUS

Your value of the social events $(=2 \times T)$ MINUS

Your tax payment for the social events $(=T)$ EQUALS

Your after-tax welfare

To determine the taxation level, the dorm's governing committee will survey its residents. They will ask which of three possible taxation levels you prefer: $\$ 0, \$ 50$, or $\$ 100$. They will then calculate the average of your choices and impose that average as the taxation level. 
Are there any questions so far?

Let's work through an example.

Imagine that there are 10 residents in your dorm, and that 2 of them vote for a level of $\$ 0$ taxes, none vote for $\$ 50$, and 8 vote for $\$ 100$. The average choice is then

$$
\frac{(2 \times \$ 0)+(0 \times \$ 50)+(8 \times \$ 100)}{10}=\$ 80
$$

so the taxation level will be $\$ 80$ for everyone in the dorm. We have used this information to calculate your after-tax welfare on the following practice worksheet:

Level of taxation chosen $(T): \$ 80$

Your spending account $\quad \$ 1,000$ PLUS

Your value of the social events $(=2 \times T) \quad \$ 160$

MINUS

Your tax payment for the social events $(=T) \quad \$ 80$

EQUALS

Your after-tax welfare

$\underline{\$ 1080}$

Are there any final questions before we begin?

Your local government will now conduct its first survey. Take a moment to think about which of the following three options you prefer:

- Taxation of $\$ 0$

- Taxation of $\$ 50$

- Taxation of $\$ 100$

After the vote is taken, we will announce the results and will then proceed to the next year.

At the beginning of each year, you will be given verbal instructions related to that particular year. Please listen carefully and do not hesitate to ask questions if you have them. 


\section{Appendix 3. Student Record Sheet}

Year 1 Level of taxation chosen $(T)$ :

Your spending account

$\$ 1,000$ PLUS

Your value of the social events $(=P V M \times T)$ MINUS

Your tax payment for the social events $(=T)$ EQUALS

Your after-tax welfare

Year 2 Level of taxation chosen $(T)$ :

Your spending account

$\underline{\$ 1,000}$ PLUS

Your value of the social events $(=P V M \times T)$ MINUS

Your tax payment for the social events $(=T)$ EQUALS

Your after-tax welfare

Year 3 Level of taxation chosen $(T)$ :

Your spending account

$\$ 1,000$ PLUS

Your value of the social events $(=P V M \times T)$ MINUS

Your tax payment for the social events $(=T)$ EQUALS

Your after-tax welfare

Year 4 Level of taxation chosen $(T)$ :

Your spending account

$\$ 1,000$ PLUS

Your value of the social events $(=P V M \times T)$ MINUS

Your tax payment for the social events $(=T)$ EQUALS

Your after-tax welfare 


\section{NOTES}

The discussion is usually found in the context of fiscal federalism. For example, see Hyman (2002), Rosen (2005), or Stiglitz (2000).

2 Tiebout's main focus is not pure public goods such as defense, but public goods that are at least partially rival in consumption (e.g., space on a crowded beach, seats in a classroom). Such services are sometimes characterized as publicly provided private goods (e.g., see Rosen).

${ }^{3}$ Tiebout also lists two other assumptions. He excludes employment factors from the analysis and also imposes the assumption that city planners try to achieve the efficient community size. This last assumption is equivalent to minimizing the average cost of production of the local public good in each community.

${ }^{4}$ We chose dorm parties as our local public good because, like the goods that are the focus of Tiebout's work, they are provided locally (within a single dorm or hallway) but are partially rival in consumption. During the post-experiment discussion, the instructor may choose to elicit from students how parties might be considered public goods without being pure public good—for example, while entertainment and decorations tend to be nonrival, refreshments tend to be rival in consumption. The instructor could then ask students for examples of goods or services provided by local governments that are nonexcludable but rival. ${ }^{5}$ Note that at this point we abstract from the Tiebout model. In Tiebout's framework there exist a multitude of community planners that compete for residents by setting the level of the local public good and corresponding tax level. Consumers then choose among the different communities to find their most preferred bundle of public good level and taxes. In our framework, we have replaced the community planners by eliciting consumer preferences. Although this is technically not how Tiebout framed his model, it accomplishes the same task as Tiebout's community planners and allows for more involvement by the students in a classroom setting.

- An Excel spreadsheet for calculating social welfare, a worksheet for calculating social welfare without a computer, sample ballots to be used in larger classes, and a set of annotated instructions for the instructor can be downloaded at: http://economics.kenyon.edu/corrigan/tiebout/tiebout.htm.

Note that because the good is (partially) rival, students do not consume the entire good $n T^{*}$, but only a share of the total $T^{*}$. 


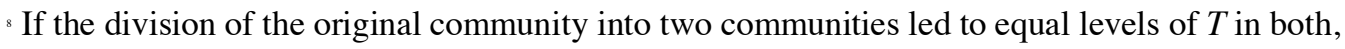
coordination would be required to find the sorting equilibrium. This could be done, but would take additional time. Hence the recommended uneven initial distribution of types (packets).

'In the authors' experience, between 90 and 100 percent of the students in each dorm will be of the expected type.

10 For those students troubled by zero net benefit being a "good" outcome, this may be a good time to clarify the idea of ordinal utility. 